\title{
CONJUNCIONES OCTAVIO PAZ/GONZALO ROJAS
}

POR

\author{
MaRcelo Coddou \\ Drew University
}

Uno de los textos más representativos de la poesía de Gonzalo Rojas, "A quien vela, todo se revela", en su versión definitiva viene precedido del epígrafe "Falo el pensamiento y vulva la palabra", verso que proviene de Blanco, poema-libro medular de la obra de Octavio Paz.

En él el mexicano indicaba la unión de eros y logos en el acto carnal. Falo, semen e iluminación: vulva, vacuidad y sabiduría. Son, en el supuesto básico del trantrismo que constituye una de las tres fuentes culturales del poemario, reflejo de los dioses, y su unión es el arquetipo hermafrodita, el Absoluto no diferenciado. La cópula, según recordara el propio Paz, citando a Mircea Eliade, es samarasa, "identité de jouissance: fusión del sujeto y del objeto, regreso al uno" (1969:70).

Si en Paz es posible establecer tal fuente hindú, ${ }^{1}$ en Gonzalo Rojas sin duda ha pesado, al recoger este verso de uno de sus poetas predilectos, un fondo de pensamiento trinitario cristiano, al que también remiten palabra y pensamiento. En efecto: según la concepción cristiana, el Padre se piensa eternamente y este pensar se expresa como su palabra, su Hijo, y el amor entre los dos es el Espíritu Santo. ${ }^{2}$ Hay una relación estructural entre la "palabra" y el "pensar": un espíritu, un amoroso soplo de aire que lleva al poema desde el silencio por boca del poeta-hacedor y lo vacía en la página. Para Rojas el aire es el elemento sacro, imagen de la poesía, y, cuando se refiere a ésta en sus relaciones concretas, siempre habla de "pensamiento poético", rara vez de poesía sola. ${ }^{3}$

Por otra parte, no olvidemos que etimológicamente palabra proviene de parábola, en griego "comparar", "hacer símiles" (Corominas 616). En este sentido la "palabra" es mediadora entre contrarios y vehículo de su unión. Com-parar es establecer diferencias y semejanzas entre dos o más cosas. La palabra - y así es como se la concibe en la poesía de Rojas - viene a ser vehículo de unión, precisamente por esa su función comparativa, establecedora de las analogías a que Octavio Paz ha consagrado tan lúcidas disquisiciones.

\footnotetext{
${ }^{1}$ Lo que en Blanco no niega, sino que se suma a la mexicana indígena y a la constituida por la tradición mística cristiana, según lo ha demostrado Joseph Feustle (1978: passim).

${ }^{2}$ Etimológicamente "espíritu" es soplo, aire (Corominas 395).

${ }^{3}$ Hemos estudiado con atención estos aspectos en nuestros dos libros dedicados al poeta chileno (1984 y 1986).
} 
Tal función supone un proceso: el pensar, que etimológicamente es "pesar cuidadosamente el pro y el contra" (Corominas 450). Este proceso mental de ir entre el pro y el contra es la actualización del vehículo que es la palabra, una mediación entre dos polos opuestos. Decimos ir entre dos polos, lo cual sugiere dos conceptos análogos, ambos centrales en la poesía del autor de Contra la muerte: ciclo y ritmo.

Referirse a este aspecto significa tocarse con reflexiones en torno a las semejanzas y diferencias entre poesía y religión. Entre los pensadores hispanoamericanos nadie ha llegado más a fondo del asunto que Octavio Paz. En el ensayo que dedicara al cuarto centenario del nacimiento de San Juan de la Cruz - bajo cuyo signo, no dejamos de recordarlo, se configuró la primera sección de Oscuro- Octavio Paz diría:

Religión y poesía tienden a la comunión, las dos parten de la soledad e intentan, mediante el alimento sagrado, romper la soledad y devolver al hombre su inocencia (1971: 98).

Propósito de ambas - religión y poesía - según Paz, el diálogo y la unión. En la religión con Dios o lo Absoluto; en la poesía, del poeta "con su propia alma, la amada, Dios, la Naturaleza". Pero sobre las diferencias también especula Paz: la religión es "conservadora", "social", a excepción de cuando se manifiesta como mística: no sólo no devuelve al hombre su inocencia, sino que le revela la pérdida de ella. La poesía, en cambio, es "disidente", "individual" y revela al hombre su innata inocencia. La religión institucionalizada plantea al hombre una eternidad y un absoluto existentes en el más allá. Los poetas, por el contrario, "han sido los primeros que han revelado que la eternidad y lo absoluto no están más allá de nuestros sentidos sino en ellos mismos" (1971: 101). ¿No es eso lo que, en definitiva, Gonzalo Rojas nos propone al contestar a la pregunta de la Mistral "¿Será esto la eternidad / que aún estamos como estábamos?", afirmando "Pero la eternidad es esto mismo"? (Rojas, 1977: 9 y 214).

Según Octavio Paz la religión, el amor y la poesía son, todos, experiencias poéticas:

Los primeros en admitir el origen común del amor, religión y poesía fueron los poetas ... Las tres experiencias son manifestaciones de algo que es la raíz misma del hombre. En las tres late la nostalgia de un estado anterior. Y ese estado de unidad primordial, del cual estamos siendo separados a cada momento, constituye nuestra condición original, a la que una y otra vez volvemos (1967: 135-136).

A ese denominador que es común a la religión y a la poesía, Octavio Paz, el ensayista, la designara como "la fuerza secreta del mundo" diciendo que:

el poeta no sólo la descubre y se hunde en ella: la muestra en toda su aterradora y violenta desnudez al resto de los hombres, latiendo en su palabra, viva en ese extraño mecanismo de encantamiento que es el poema (1971: 100).

Describe la naturaleza de esa fuerza - "alternativamente sagrada o maldita"- como la del éxtasis, o la del vértigo, "que brota como una fascinación de la cima del contacto carnal o espiritual". Esta aproximación enlaza con lo Absoluto, vislumbra la reconciliación muerte- 
vida y reintegra a la energía original: todos problemas cardinales en la poesía de Gonzalo Rojas (Coddou, 1984 y 1986, passim). Leemos en Paz:

en lo alto de ese contacto y la profundidad de ese vértigo el hombre y la mujer tocan lo absoluto, el reino en donde los contrarios se reconcilian y la vida y la muerte pactan en unos labios que se confunden. El cuerpo y el alma, en ese instante, son lo mismo y la piel es como una nueva conciencia, conciencia de lo infinito [...] El tacto y todos los sentidos dejan de servir al placer o al conocimiento: así, y lejos de constituir las antenas, los instrumentos de la conciencia, la disuelven en lo absoluto, la reintegran a la energía original (1971: 100-101).

El sexo, pues, va más allá de toda dualidad y en la relación intersexual se reconcilian los contrarios, lo que conduce a la relación arquetípica:

la unión de los cuerpos - leemos en otro ensayo de Paz-y de los opuestos es asimismo la realización del arquetipo hermafrodita (1969: 79).

A esta luz, estimo, es que debe considerarse el poema "Playa con adróginos" de Gonzalo Rojas (1979: 76):

A él se le salía la muchacha y a la muchacha él por la piel espontánea, y era poderoso ver cuatro en la figura de estos dos que se besaban sobre la arena; vicioso era lo viscoso o al revés; la escena iba de la playa a las nubes.

Qué después

pasó; quién entro en quién?; hubo sábana con la mancha de ella y él ¿fue la presa?

del goce ríen ahí

$\mathrm{O}$ atados a la deidad

no más su relincho de vivir, la adolescencia de su fragancia?

Recordemos que en el mito de Andrógino se trata de la dualidad integrada, lo que implica la perfección. "Andrógino" es una divinidad esencialmente engendradora y característica de los estados primigenios de la mitología. Cirlot nos advierte:

Psicológicamente, no se debe descuidar que la idea de androginia representa una fórmula (por aproximación, como casi todas las fórmulas míticas), de la "totalidad", de la "integración de los contrarios" (1979: 67).

Pero no sólo por allí van las conjunciones Gonzalo Rojas/Octavio Paz: hay otras dimensiones de la obra de ambos que guardan relación entrañable. El poeta-ensayista mexicano, en uno de los tantos trabajos que ha dedicado al surrealismo, volverá a enlazar 
poesía y amor, concibiéndolos como inseparables (notemos, de paso, la idea de poesía activa, que el escritor chileno llegaría a propiciar como la más auténtica). Escribe Paz:

\begin{abstract}
Poesía y amor son actos semejantes. La experiencia poética y la amorosa nos abren las puertas a un instante eléctrico. Allí el tiempo no es sucesión, ayer, hoy y mafiana dejan de tener significado: sólo hay un siempre que es también un aquí y un ahora. Caen los muros de la prision metal, espacio y tiempo se abrazan, se entretejen y despliegan a nuestros pies una alfombra viviente, una vegetación que nos cubre con sus mil manos de hierba, que nos desnuda con sus mil ojos de agua. El poema, con el amor, es un acto en el que nacer y morir, esos dos extremos contradictorios que nos desgarran y hacen de tal modo precaria la condición humana, pactan y se funden (1971: 148). ${ }^{4}$
\end{abstract}

En suma, poesía y amor, permiten la unión de los contrarios, llevan a la transmutación del hombre y se convierten así en vehículo de trascendencia. ${ }^{5}$ Tanto en el autor de Blanco como en el poeta de Oscuro se percibe esa identidad entre la experiencia poética y la del amor; en ambos precisamente a partir de una conciencia asumida de la escisión, que les impulsa a la búsqueda de la unión, búsqueda que en definitiva es del fundamento.

Esa búsqueda del Fundamento -que con tanta perspicacia percibiera Jaime Concha, en un trabajo de hace años, en la poesía residenciaria de Neruda y que José Promís ha destacado como rasgo generacional de los escritores chilenos que Cedomil Goiç denomina "del 42"- es característica de nuestra época, según dice el propio Paz:

nuestro tiempo es el de la búsqueda del fundamento, o, como decía Hegel, el de la conciencia de la escisión (1968: 7).

La oposición escisión / unión se resuelve, en Gonzalo Rojas - hasta una lectura rápida de su obra puede constatarlo- en la experiencia que se obtiene a través del amor y de la poesía. Poesía y amor que son una religión para el poeta de La miseria del hombre, esto es, una manera de religar los elementos contrarios que pueden reintegrar al hombre a la energía original de la cual se siente escindido. Vehículo de trascendencia y mediadores en Gonzalo Rojas: el poema, la mujer, la palabra.

Como otra muestra más este poema de Rojas (1979: 93) donde lo corporal, el saber y la poesía trascienden en anhelo de permanencia por medio del gesto erótico-sacramental:

"A esa que va pasando ahi"

Religo lo religioso de tus piernas a la sabiduría alta de respirarte, mi aleteante, a ti

te lo dice la nariz que soy, $\mathrm{mi}$

\footnotetext{
${ }^{4}$ En El arco y la lira puede leerse: "el poema no sólo proclama la coexistencia dinámica y necesaria de los contrarios, sino su final identidad" (1967: 101).

${ }^{5}$ Feustle, en el extenso capítulo dedicado a Paz de su libro citado, estudia con toda detención este aspecto.
} 
cartilago casi

la costilla que alguna vez, el hueso

que seremos si somos. ${ }^{6}$

El núcleo cardinal de la poesía de Gonzalo Rojas, el que opera como centro movilizador del quehacer y del pensamiento poético suyos, es esta búsqueda. Así deben entenderse, nos parece, afirmaciones suyas como las que citaremos, a veces aparentemente disímiles entre ellas - y pueden llegar a serlo en sus formulaciones concretas - pero que siempre apuntan a lo mismo: aun cuando aparezcan teñidas de "psicologismo" procuran una dimensión ontológica. Oigámoslo:

Quiero decirlo de una vez: me duele este oficio. Aunque no haya nunca otro mayor, como está escrito en el relámpago; ni el que te hace sabio ni el que te hace poderoso, pero hay que merecerlo. No transar con el éxito ni con la adversidad. Porque, dicha o desdicha, todo es mudanza para ser. Para ser, y más ser; y en eso andamos los poetas (1981: 9).

$\mathrm{Y}$, en otro lado, con parecidos términos:

porque uno nace y se está yendo siempre para ser, para ser y más ser, en la mudanza de la aproximación y ahí está acaso la videncia del poeta, en el non omnis moriar, no me moriré del todo, pese a la dicha o la desdicha (Maack 1980).

También esta otra frase suya, tan conocida:

en lo que he escrito, he tratado de ver el parentesco que existe entre la variedad infinita de las cosas (Ríos 1970: 110).

$\mathrm{Y}$ en su definición de lo que pretende el libro Transtierro (en verdad toda su obra):

Aspira a mostrar, y sólo a mostrar, la muerte-vida como búsqueda del origen, una constante que viene obsesiva desde mi Cuaderno Secreto, de 1936 (Ramírez 1979: 44).

No cabría casi insistir en más formulaciones explícitas, teniendo a la vista la obra misma del poeta, en que tal búsqueda se nos revela, efectivamente, obsesiva. Más bien lo que quisiéramos señalar - no más que eso- es la filiación surrealista de tal postura. Testimonios suyos sobre ello son innumerables; como muestra, éste:

su línea [la del surrealismo] no la he dejado en cuanto a actitud de fundamento y por qué no decirlo, de conducta (Gaytán 1980: 10).

El entronque de Gonzalo Rojas con el surrealismo - tema al cual dedicáremos extenso capítulo de nuestro libro de 84- permite, en efecto, aproximar cabalmente su obra a la de Octavio Paz. Fue éste precisamente quien dice ver en la poesía del autor de Del relámpago:

${ }^{6}$ Sobre este poema consultar Carlos Cortínez (1979: 359-367). 
una afirmación - brutal, desesperada - que engloba a la muerte y la vida. En todo caso más que de antítesis habría que hablar de paradoja, en el sentido de Kierkegaard: salto mortal de una orilla a la otra. ${ }^{7}$

Los mismos impulsos que movieron la escritura de Blake y que están presentes en el autor de Libertad bajo palabra y en los surrealistas, alientan en la obra de Gonzalo Rojas: sus tentativas que, en lucha con los opuestos, intentan la primera enunciación. Para el poeta chileno, como para Paz y los surrealistas, la poesía no puede ser mera "expresión del yo sino la (re) conquista del ser"."

En esa búsqueda - ciega, tartamuda en los hablantes líricos de muchas composiciones de Gonzalo Rojas - que es búsqueda de un sistema de relaciones poéticas, de un orden nuevo, de analogías nuevas, se plantea también la opción de un pensamiento poético nuevo. Rojas lo encuentra formulado precisamente en Octavio Paz, sobre quien ha dicho:

es el escritor lúcido que piensa hoy pensamiento original como ninguno (Maack 1980).

Si espigamos en la obra de éste, nos encontramos con una serie de afirmaciones que nos muestran su concepción que algunos han llamado "lingüística" de la realidad. Para Paz el lenguaje es, en sí, aventura intelectual. Por su medio nos ciframos -autor y lector-y nos desciframos, esto es, buscamos en él nuestro origen e interpretamos la realidad que nos nombra. Citemos una muestra de esta concepción:

Cada persona es una lectura de la realidad; esa lectura es una traducción; esa traducción es una escritura; un volver a cifrar la realidad que se descifra. El poema es un doble del universo; una escritura secreta, un espacio cubierto de jeroglíficos. Escribir un poema es descifrar al universo para cifrarlo de nuevo (1974). ${ }^{9}$

En muchos lugares de Libertad bajo palabra se nos propone a ésta como protagonista de la realidad que nos inventa y el hombre que la enuncia, inventándose a través de ella. "Contra el silencio y el bullicio inventó la Palabra, libertad que se inventa y me inventa cada día", dice Paz (1979:18). En tal presupuesto, interpreta Antonio Carreño, se constituye el lenguaje en:

protagonista de la radical contradicción humana entre el querer ser (o significar) y el negarlo en toda afirmación (aquella voluntad de afirmación de que habla Nietzsche); del vacío existente entre las dualidades vida-muerte, tiempo-eternidad, o de la fusión de los contrarios (1979).

Toda la obra de Gonzalo Rojas se asienta sobre tales "paradojas" - en el sentido de Kierkegaard recordado por Paz-: los contrastes tiempo/eternidad, oscuridad/luz, tierra/

\footnotetext{
${ }^{7}$ Carta de Octavio Paz a Gonzalo Rojas fechada en México el 9 de febrero de 1978. Cito por una copia de mi archivo.

${ }^{8}$ Véase esta conclusión sobre Paz en Guillermo Sucre (1975: 220).

${ }^{9}$ Consúltese Monique Lemaître (1976) y Antonio Carreño (1979).
} 
paraíso, concreto/trascendencia. Esos lejanos versos suyos que, no por casualidad, figuran como apertura de Trastierro, verdadero manifiesto, que dicen:

\author{
Vivo en la realidad. \\ Duermo en la realidad. \\ Muero en la realidad. \\ Yo soy la realidad. \\ Tú eres la realidad. \\ Pero el sol \\ es la única semilla,
}

ilustran, mejor que cualesquiera otros, en su fuerte adversativo, la constante apetencia de ascensión a lo trascendente. Y la configuración de las contradicciones y el intento de llenar el vacío entre ellas, confiado a la palabra. Lenguaje que es en sí vida y conocimiento poético. Palabra que es la que nos afirma ontológicamente: fusiona ella los opuestos, permite las correspondencias analógicas y el salto en la búsqueda de la afirmación del Ser.

Para dar definitiva validez a esta simple sugerencia que aquí hemos esbozado sobre la confluencia en aspectos decisivos del pensamiento poético de Octavio Paz y Gonzalo Rojas, nos falta el análisis de textos. Tal revisión demostraría que la dialéctica entre la dispersión y la unidad, la fusión y la ruptura, no son presencia que se reduzca al nivel temático en las obras de ambos poetas, sino que llegan a constituirse en su estructura misma y, así, en su cosmovisión.

\title{
BIBLIOGRAFÍA
}

Carreño, Antonio. "La máscara como diagrama: Vuelta". Cuadernos Hispanoamericanos, 343/345. México, 1979.

Coddou, Marcelo. Poética de la poesía activa. Madrid: LAR, 1984.

Nuevos estudios sobre la poesía de Gonzalo Rojas. Santiago: Sinfronteras, 1986.

Cirlot, J.E. Diccionario de simbolos. Barcelona: Labor, 1979.

Corominas, J. Breve diccionario etimológico de la lengua castellana. Madrid: Gredos, 1967.

Cortínez, Carlos. "La salvación, de Gonzalo Rojas". Revista Iberoamericana 106/107 (1979) 359-367.

Feustle, Joseph A. Poesía y mística (Dario, Jiménez y Paz). Xalapa: Universidad Veracruzana, Cuadernos de Texto Crítico, 1978.

Gaytán, Sergio. "Trastierro, de Gonzalo Rojas". El Mercurio (Antofagasta, 29 mayo 1980).

Lemaître, Monique. Octavio Paz: poesía y poética. México: UNAM, 1976.

Maack, Ana María. "Gonzalo Rojas. Entrevista”. El Sur (Concepción, 10 febrero 1980).

Paz Octavio. El arco y la lira. Mexico: Fondo de Cultura Económico, 1967. Corriente Alterna. México: Siglo XXI, 1968.

Conjuciones y disyunciones. México: Joaquín Mortiz, 1969.

Las peras del olmo. Barcelona: Seix Barral, 1971. 
Teatro de Signos/Transparencias. Selección y montaje de Julián Ríos. Madrid: Fundamentos, 1974.

Poemas 1935-1975. Barcelona: Seix Barral, 1979.

Ramírez, Enrique. "El 'trastierro' de un poeta". Hoy (Santiago, 19-25 septiembre 1979) 44-45.

Ríos, Patricio. "Notas sobre una poesía. Entrevista a Gonzalo Rojas". Aisthesis. Revista de investigaciones estéticas de la Universidad Católica, 5 (Santiago, 1970): 108130.

Rojas, Gonzalo. Oscuro. Caracas: Monte Ávila, 1977.

Trastierro (versión antológica). Madrid: Ediciones Nos Queda La Palabra, 1979. Del relámpago. México: Fondo de Cultura Económica, 1981.

Sucre, Guillermo. La máscara, la transparencia. Caracas: Monte Ávila, 1975. 